\title{
From the HINDAS Project: Excitation Functions for Residual Nuclide Production by Proton-Induced Reactions
}

\author{
R. Michel ${ }^{1}$, M. Gloris ${ }^{1}$, J. Protoschill ${ }^{1}$, M.A.M. Uosif ${ }^{1}$, M. Weug ${ }^{1}$, \\ U. Herpers ${ }^{2}$, J. Kuhnhenn ${ }^{2}$, P.-W. Kubik ${ }^{3}$, D. Schumann ${ }^{4}$, H.-A. Synal ${ }^{4}$, \\ R. Weinreich ${ }^{4}$, I. Leya ${ }^{5}$, J.C. David ${ }^{6}$, S. Leray ${ }^{6}$, M. Duijvestijn ${ }^{7}$, A. Koning ${ }^{7}$, \\ A. Kelic ${ }^{8}$ K.H. Schmidt ${ }^{8}$, and J. Cugnon ${ }^{9}$ \\ ${ }^{1}$ Center for Radiation Protection and Radioecology, University Hanover, Germany, ${ }^{2}$ Dept. for Nuclear Chemistry, \\ University of Cologne, Germany, ${ }^{3}$ Institute for Particle Physics, ETH Hönggerberg, Zurich, Switzerland, \\ ${ }^{4}$ Paul Scherrer Institute, Villigen, Switzerland, Institute for Isotope Geology and Mineral Resources, ETH Zürich, \\ Zurich, Switzerland, ${ }^{6}$ CEA-Saclay, France, ${ }^{7}$ Nuclear Research and Consultancy Group, Petten, The Netherlands, \\ ${ }^{8}$ GSI, Darmstadt, Germany, ${ }^{9}$ Université de Liège, Belgium
}

\begin{abstract}
A survey is given about efforts undertaken during the HINDAS project to investigate the energy dependence of residual nuclide production by proton-induced reactions from thresholds up to $2.6 \mathrm{GeV}$. For proton-induced reactions, our experiments aimed to further develop and complete the cross-section database that was established by our collaboration in recent years. It was extended to the heavy-target elements $\mathrm{Ta}, \mathrm{W}, \mathrm{Pb}$, and $\mathrm{Bi}$ for energies up to $2.6 \mathrm{GeV}$. In addition, new measurements for the target element iron were performed up to $2.6 \mathrm{GeV}$ and for natural uranium for energies from $21 \mathrm{MeV}$ to $69 \mathrm{MeV}$. For the target element lead, a comprehensive set of excitation functions published recently was completed by AMS-measurements of cross sections for the production of the long-lived radionuclides Be-10, Al-26, Cl-36, and I-129 and by mass spectrometric measurements for stable and radioactive rare gas isotopes of $\mathrm{He}, \mathrm{Ne}, \mathrm{Ar}, \mathrm{Kr}$, and Xe. Comprehensive tests of the nuclear-reaction codes TALYS and INCL4+ABLA, which were developed within the HINDAS project, were performed with the new experimental results over the entire energy range.
\end{abstract}

\section{INTRODUCTION}

For accelerator technologies, production of residual nuclides has to be described to model the radioactive inventories of the spallation targets, the activation of accelerating structures, of the beam pipes and windows and of shielding materials, cooling materials and ambient air. Radionuclide inventories will determine the final disposal costs of spallation targets and will decide whether or not the burn-up of nuclear waste can be counterweighted by the creation of other activation products. Moreover, intermediate energy cross sections of fission products and actinides are needed. Finally, the production of residual nuclides will cause chemical alteration of the irradiated components and, in particular, production of light complex particles such as ${ }^{2} \mathrm{H},{ }^{3} \mathrm{H},{ }^{3} \mathrm{He}$, and ${ }^{4} \mathrm{He}$ will cause considerable material damage.
Integral excitation functions for the production of residual nuclides are basic quantities for the calculation of radioactive inventories of spallation targets in spallation neutron sources and in accelerator-driven devices for energy amplification or for transmutation of nuclear waste. Due to the large range of relevant target elements and the vast amount of product nuclides it will not be possible to measure all the cross sections needed. Consequently, one will have to rely widely on models and codes to calculate the required cross sections and validation of such calculations will be a high priority issue. Since previous experiences with predictions of such excitation functions were not satisfying [1], two new code systems were developed within the HINDAS (High and Intermediate Energy Nuclear Data for Accelerator-Driven Systems) project [2]. Experimental investigations of the HINDAS project provided consistent sets of nuclear data of all types to allow for comprehensive tests of these 
models; see [3] for details. Here, we report the respective work for the production of residual nuclides by proton-induced reactions up to $2.6 \mathrm{GeV}$.

\section{EXPERIMENTAL DATABASE}

For proton-induced reactions, the efforts of the HINDAS project aimed to further developing and completing the cross section database that was established by our collaboration in recent years; see [4] and references therein. During the HINDAS project the database was extended to the heavy-target elements $\mathrm{Ta}, \mathrm{W}, \mathrm{Pb}$, and $\mathrm{Bi}$ [5-8]. Further, about 560 new cross sections for the production of 19 radionuclides from the target element iron have been measured from thresholds up to $2.6 \mathrm{GeV}$. For the target element lead a comprehensive set of excitation functions published recently was completed by AMS measurements of cross sections for the production of the long-lived radionuclides ${ }^{10} \mathrm{Be},{ }^{36} \mathrm{Cl}$, and ${ }^{129} \mathrm{I}$, (Schumann et al., these proceedings). For natural uranium, cross sections for the production of residual nuclides are available for p-energies from $21 \mathrm{MeV}$ to $69 \mathrm{MeV}$ (Uosif et al., these proceedings) and at $600 \mathrm{MeV}$ (Adam et al., these proceedings), and evaluations of past irradiation experiments of thorium and uranium at Saturne for energies between $200 \mathrm{MeV}$ and $2.6 \mathrm{GeV}$ are underway. Further spin-offs of the HINDAS project were mass spectrometric measurements of cross sections for the production of stable and radioactive isotopes of $\mathrm{He}, \mathrm{Ne}, \mathrm{Ar}$, $\mathrm{Kr}$, and Xe from natural lead [9].

Together with not-yet published cross sections for the target elements $\mathrm{Rb}, \mathrm{Mo}, \mathrm{Rh}, \mathrm{Ag}, \mathrm{In}, \mathrm{Te}$, and $\mathrm{La}$, our entire consistent database now covers the target elements C, N, O, Mg, Al, Si, Ca, Ti, V, Mn, Fe, Co, $\mathrm{Ni}, \mathrm{Cu}, \mathrm{Rb}, \mathrm{Sr}, \mathrm{Y}, \mathrm{Zr}, \mathrm{Nb}, \mathrm{Mo}, \mathrm{Rh}, \mathrm{Ag}, \mathrm{In}, \mathrm{Te}, \mathrm{Ba}, \mathrm{La}$, $\mathrm{Ta}, \mathrm{W}, \mathrm{Au}, \mathrm{Pb}, \mathrm{Bi}$, and $\mathrm{U}$. It contains data for nearly 1,500 nuclear reactions and more than 25,000 cross sections. Most of the data are available in EXFOR.

Our investigations made use of classical kinematics and, therefore, they are confined to residual nuclides with usually at least a few hours' half-lives that mostly reveal a cumulative production due to the decay of short-lived progenitors. These investigations are complimentary to those using inverse kinematics where the primary residuals can be studied at certain energy points, e.g., [10]. The classical kinematics allows studying the energy dependence from thresholds up to the highest energies, which are $2.6 \mathrm{GeV}$ for protoninduced reactions of this work. The data obtained by this method are the basis to test whether the energy dependence of nuclear reaction phenomena are properly taken into account by nuclear models and codes.

\section{MODEL VALIDATION}

During the HINDAS project two code systems were developed to satisfy the needs for modelling nuclear reaction data at intermediate and high energies. The TALYS code includes the optical model, direct, pre-equilibrium, fission, and statistical models and thereby gives a prediction for all the open reaction channels for energies up to about $200 \mathrm{MeV}$ (Koning et al. in these proceedings). The INCL4+ABLA code system is a combination of the codes INCL4 [11] for the intra-nuclear cascade and ABLA [12] for the nucleus de-excitation. The experimental database established during the HINDAS project offers an excellent chance for the validation of the new codes.

To validate these code systems with respect to their capabilities to predict cross sections for the production of residual nuclides respective "blind" calculations were performed for $\mathrm{Fe}, \mathrm{W}, \mathrm{Ta}, \mathrm{Pb}, \mathrm{Bi}$, and $\mathrm{U}$ and the results were compared with the new experimental data.

Figure 1 gives an example for such a comparison for the production of ${ }^{52 \mathrm{~m}+\mathrm{g}} \mathrm{Mn}$ from natural iron. A more systematic survey on the capabilities of the TALYS and INCL4+ABLA codes and on stillpertaining problems is given in Fig. 2 for the target element bismuth. Generally, the results of these comparisons were quite good. For a wide range masses from target near to spallation products, both codes, TALYS and INCL4+ABLA, adequately reproduce the experimental cross sections varying by 5 orders of magnitude over the entire range of energies. In contrast to earlier evaluations [4-8], the new codes also give reasonable results for all fission products.

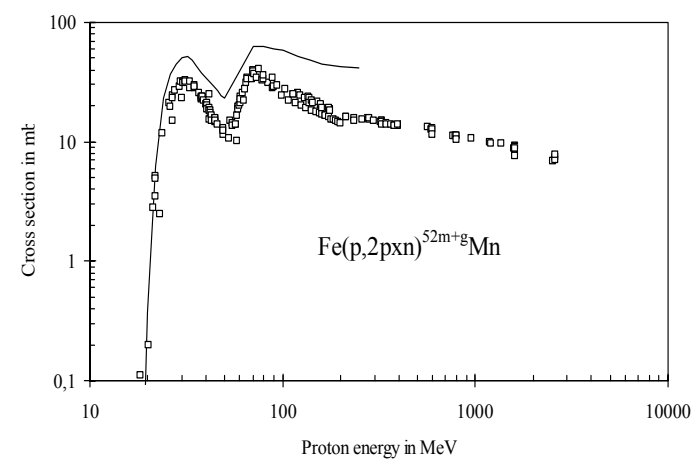

FIGURE 1. Experimental cross sections (squares) for the production of ${ }^{52 \mathrm{~m}+\mathrm{g}} \mathrm{Mn}$ from natural iron by proton-induced reactions in comparison with TALYS results (solid line). 

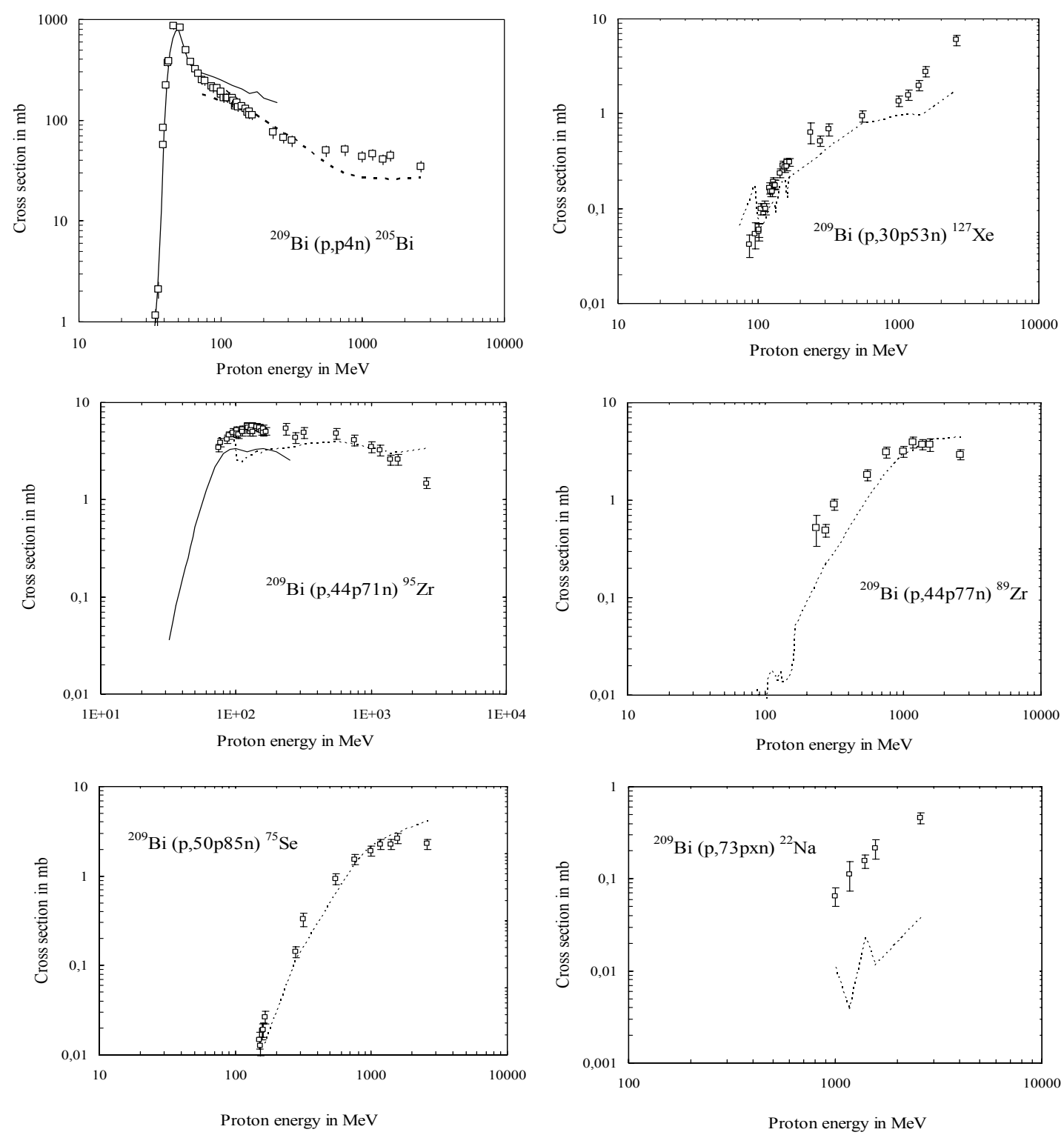

FIGURE 2. Comparison of experimental cross sections [7] with model calculations using the TALYS (solid lines) and INCL4+ABLA (broken lines) codes.

There remains, however, a problem with the production of light products. Already the production of ${ }^{22} \mathrm{Na}$ from $\mathrm{Bi}$ is underestimated by about an order of magnitude. These discrepancies get worse for lighter target masses as e.g., ${ }^{7} \mathrm{Be}$ and ${ }^{10} \mathrm{Be}$. We attribute them to the neglect of multi-fragmentation in the existing codes.
The production of noble gas isotopes in lead by proton-induced reactions is of special importance for design studies of accelerator driven systems and energy amplifiers. Such measurements were performed within the HINDAS project by direct measurement of light gas isotopes by the NESSI collaboration, e.g., [13]. In addition and in order to test the 
consistency with earlier mass spectrometric measurements the production of stable and radioactive rare gas isotopes of $\mathrm{He}-, \mathrm{Ne}-, \mathrm{Ar}-, \mathrm{Kr}-$, and $\mathrm{Xe}$ from natural lead by proton-induced reactions was investigated from threshold up to $2.6 \mathrm{GeV}$ by rare gas mass spectrometry [9]. Apart from some exceptions the database for the proton-induced production of noble gas isotopes from lead is consistent and nearly complete. While for the production of $\mathrm{He}$ from $\mathrm{Al}$ and $\mathrm{Fe}$, where the cross sections obtained by thin-target irradiation experiments are up to a factor of 2 higher than the NESSI data, both datasets agree for the He production from lead (Fig. 3).

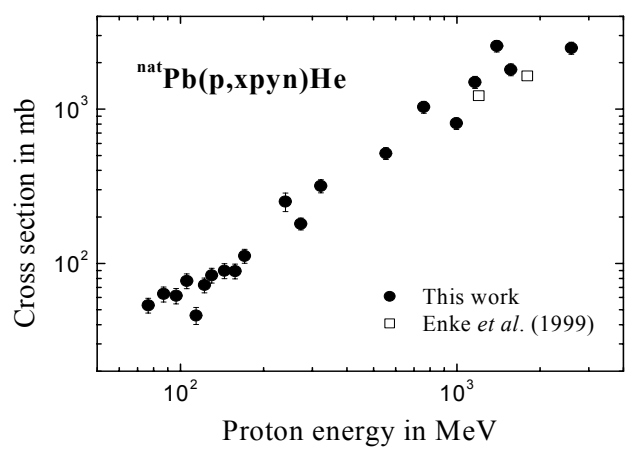

FIGURE 3. Production of $\mathrm{He}\left(={ }^{3} \mathrm{He}+{ }^{4} \mathrm{He}\right)$ from Lead by proton-induced reactions; data are from [9] (full circles) and [13] (open squares).

\section{CONCLUSIONS}

Cross sections for the production of residual nuclides are a key issue for medium energy applications. Since it is impossible to measure all cross sections needed for accelerator driven technologies, models and codes have to be improved to meet the accuracy requirements of the applications. Databases of experimental cross sections are improving, but do not sufficiently cover all reaction modes and data needs. Experimental cross sections provide the benchmarks for models and codes and much can already be done on the basis of the now existing experimental databases. But, more remains to be done in the future.

\section{ACKNOWLEDGMENTS}

The authors thank the authorities of LNS Saturne, PSI, and TSL for the beam time and the accelerator staffs for their kind co-operation. This work was funded by the EC $6^{\text {th }}$ Framework project HINDAS.

\section{REFERENCES}

1. Michel, R., and Nagel, P., NSC/DOC (97)-1, NEA/OECD, Paris (1997).

2. Koning, A., Beijers, H., Benlliure, J., Bersillion, O., Cugnon, J., Duijvenstein, M., Eudes, Ph., Filges, D., Haddad, F., Lebrun, C., Lecolley, F.-R., Leray, S., Meulders, J.-P., Michel, R., Neef, R., Nolte, R., Olsson, N., Ramström, E., Schmidt, K.-H., Schuhmacher, H., Slypen, I., Synal, H.-A., and Weinreich, R., Nucl. Sci. Techn., Suppl. 2, 1161-1166 (2002).

3. Kelic, A., and Schmidt, K.-H. (eds.) Proc. Int. Workshop on Nucl. Data for the Transmutation of Nuclear Waste, http://www-wnt.gsi.de/tramu/Proceedings.htm, (2004).

4. Michel, R., Bodemann, R., Busemann, H., Daunke, R., Gloris, M., Lange, H. J., Klug, B., Krins, A., Leya, I., Lüpke, M., Neumann, S., Reinhardt, H., SchnatzBüttgen, M., Herpers, U., Schiekel, Th., Sudbrock, F., Holmqvist, B., Condé, H., Malmborg, P., Suter, M., Dittrich-Hannen, B., Kubik, P.-W., and Synal, H.-A., and Filges, D., Nucl. Instr. Meth. B129, 153-193 (1997).

5. Gloris, M., Michel, R., Sudbrock, F., Herpers, U., Malmborg, P., and Holmqvist, B., Nucl. Phys. A463, 593-633 (2001).

6. Kuhnhenn, J., Herpers, U., Glasser, W., Michel, R., Kubik, P.W., and Suter, M., Radiochimica Acta 89, 697-702 (2001).

7. Michel, R., Gloris, M., Protoschill, J., Herpers, U., Kuhnhenn, J., Sudbrock, F., Malmborg, P., and Kubik, P.W., Nucl. Sci. Techn., Suppl. 2, 242-245 (2002).

8. Miah, M.M.H., Kuhnhenn, J., Herpers, U., Michel, R., and Kubik, P.W., Nucl. Sci. Techn., Suppl. 2, 369-372 (2002).

9. Leya, I., Wieler, R., David, J.-C., Michel, R., Nucl. Instr. Meth. Phys. Res. B (2004) submitted.

10. Enqvist, T., Wlazlo, W., Armbruster, P., Benlliure, J., Bernas, M., Boudard, A., Czajkowski, S., Legrain, R., Leray, S., Mustapha, B., Pravikoff, M., Rejmund, F., Schmidt, K.-H., Stéphan, C., Taïeb, J., Tassan-Got, L., and Volant, C., Nucl. Phys. A686, 481-524 (2001).

11. Boudard, A., Cugnon, J., Leray, S., and Volant, C., Phys. Rev. C66, Art. No. 044615 (2002).

12. Junghans, A.R., de Jong, M., Clerc, H.-G., Ignatyuk, A.V., Kudyaev, G.A., and Schmidt, K.-H., Nucl. Phys. A629, 635-655 (1998).

13. Enke, M., Herbach, C.-M., Hilscher, D., Jahnke, U., Schapiro, O., Letouneau, A., Galin, J., Goldenbaum, F., Lott, B., Péghaire, A., Filges, D:, Neef, R.-D., Nünighoff, K., Paul, N., Schaal, H., Sterzenbach, G., Tietze, A., and Pienkowski, L., Nucl. Phys. A657, 317-339 (1999). 